[Agr. Biol. Chem., Vol. 34, No. 7, p. 1020 1028, 1970]

\title{
Polarographic Behavior of Thiolated Natural and Synthetic Polymers ${ }^{\dagger}$
}

\author{
By Toyo Kuninori and Hiroshi Matsumoto \\ Osaka Women's University, Sumiyoshi-ku, Osaka \\ Received November 19, 1969
}

\begin{abstract}
Polarographic protein waves were studied by using model samples. Two samples were prepared by thiolation of natural and synthetic polymers which show no catalytic wave in the ammoniacal cobalt buffer. The one was made from bacterial $\alpha$-amylase by thiolation with $\mathrm{N}$-acetylhomocysteine and the other was made from polyvinylalcohol by esterification with thioglycolic acid. These thiolated polymers showed typical double waves similar to protein waves both in cobaltous and cobaltic media though minute differences were present between the waves of thiolated polyvinylalcohol and those of proteins.
\end{abstract}

Since Brdička discovered that the double waves appeared in the ammoniacal cobaltous electrolyte containing human serum, " they were named "protein waves" and have been studied by many investigators."

It has been known that the waves are due to the catalytic reduction of hydrogen ions with thiol groups in the protein molecule which are originally contained or are formed from disulfide groups by their electroreduction on the surface of the electrode. Therefore thiol or disulfide groups seem to be essential for producing the catalytic waves. There existed distinct differences between protein and cystine waves, that is, the former is double waves and appears both in cobaltic and cobaltous media, whereas the latter is single and appears only in the cobaltous medium. It has been shown that the presence of polymers such as polyethyleneglycol and methylcellulose changes cystine wave from

$\dagger$ Parts of this work were presented at the Annual Meetings of the Agricultural Chemical Society of Japan, Nagoya, April, 1968.

1) R. Bridicka, Coll. Czech. Chem. Commun., 5, 112 (1933).

2) M. Shinagawa and H. Nezu, "The Polarography," No. 3 (Kagaku no Ryoiki, Extra issue, 69) ed. by T. Fujinaga and M. Maruyama, Nankodo Inc., Tokyo, 1965, p. 181. single to double, ${ }^{3,41}$ and also some sugars have the same effect on cystine wave. Materials which have been chemically incorporated by thiol groups seem to be interesting as the model samples for investigating "protein waves." Hata ${ }^{51}$ showed that the gelatin modified with thioglycolyl groups represented welldefined catalytic wave in cobaltic electrolyte. $\mathrm{He}$ also examined the thiolated casein and indicated that the wave height of the derivative was greater than that of original casein. Brdička et al. ${ }^{(j)}$ also studied the polarographic wave of thiolated gelatin which was prepared by treating gelatin with S-acetylthiosuccinic anhydride and observed the similar waves as shown by Hata.

Other functional groups may be worth discussing on polarographic behaviors. Sunahara et $a l^{71}$ studied polarographic behavior of the natural octapeptides, vasopressine, oxytocin

3) T. Asao, F. Ohta and S. Ueno, Abstracts of Papers, Annual Meeting of the Agricultural and Chemical Society of Japan, Tokyo, April, 1963, p. 88; T. Asao, H. Kaneko and K. Takebayashi, ibid., Sapporo, July, 1964, p. 49.

4) H. Nezu, Rev. Polarog. (Kyoto), 10, 154 (1962),

5) T. Hata, Ph. D. Thesis, Kyoto University (1954).

6) R. Brdicka, J. Homolka and J. Skachova, Rev. Roumanie Biochim., 3, 35 (1966).

7) H. Sunahara, D. N. Ward and A. C. Griffin, J. Am. Chem. Soc., 82, 6017, 6023 (1960). 
and their benzyl or acetyl derivatives. The correlation of their catalytic effect and their functional groups were discussed.

The present experiments were undertaken to determine a role of thiol and disulfide groups on the "protein wave." Thiolated $\alpha$ amylase was prepared by modification of bacterial $\alpha$-amylase with $\mathrm{N}$-acetylhomocysteine $^{81}$ and thioglycolated polyvinylalcohol was prepared by partial esterification of polyvinylalcohol with thioglycolic acid." These samples may have a great meaning for the polarographic study. The former is a derivative from a pure protein and the latter is a derivative from the polymer which has neither amino nor carboxyl groups.

\section{MATERIALS AND METHODS}

Reagents. Crystalline bacterial $\alpha$-amylase was purchased from Nagase Industrial Co., Amagasaki. NAcetylhomocysteine thiolactone (AHTL) was obtained from Mann Research Laboratories, New York. Polyvinylalcohol, Gosenol NL 025, was purchased from the Nippon Synthetic Chemical Industry Co., Ltd., Amagasaki. Thioglycolic acid, ammonium chloride, and ammonia were the analytical-grade products of Wako Pure Chemicals Co., Osaka. Hexamminecobaltic chloride and cobaltous chloride were recrystallized from commercial products.

Polarography. Yanagimoto-pen recording polarograph, model PA-102 (maximum sensitivity, 0.002 $\mu \mathrm{A} / \mathrm{mm}$ ) was employed. Standard electrolyte contains $1 \mathrm{mM}$ cobalt, $\mathrm{M} / 10$ ammonium chloride and $\mathrm{M} / 10 \mathrm{am}-$ monia. Stock solution of electrolyte was daily prepared by mixing each $2 \mathrm{ml}$ of $10 \mathrm{~mm}$ cobalt salt, $1 \mathrm{M}$ ammonium chloride, $1 \mathrm{M}$ ammonia and filling up to $10 \mathrm{ml}$ with water. Analysis was started after mixing $1 \mathrm{ml}$ of the stock electrolyte and $1 \mathrm{ml}$ of sample solution-standard concentration being $0.50 \mathrm{mg}$ for thiolated $\alpha$-amylase (SH-amylase) and $0.214 \mathrm{mg}$ for thiolated PVA (SH-PVA) per $1 \mathrm{ml}-$ in the vessel and

8) R. E. Benesch and R. Benesch, Biochim. Biophys. Acta, 63, 166 (1962).

9) K. Azeyanagi and I. Sakurada, Kobunshi Kagaku, 7, $255(1950)$. driving out the dissolved oxygen by passing nitrogen gas through the solution for $3 \mathrm{~min}$. The currentvoltage curve was recorded from -0.8 volt versus mercury pool electrode. All operations were carried out at $25 \pm 0.5^{\circ} \mathrm{C}$.

Thiolation of $\alpha$-amylase. The bacterial $\alpha$-amylase was purified in order to eliminate the contaminating protease. Commercial $\alpha$-amylase ( $1 \mathrm{~g}$ ) was suspended in $50 \mathrm{ml}$ of water, and $\mathrm{N} / 20$ sodium hydroxide was added dropwise until the solution becomes clear. To the enzyme solution was added calcium acetate until final concentration reached $\mathrm{M} / 100$, and the $\mathrm{pH}$ was adjusted at 5.9 with $\mathrm{M} / 20$ acetic acid. The solution was incubated at $65^{\circ} \mathrm{C}, 30 \mathrm{~min}$. After centrifugation the supernatant was diluted with $\mathrm{M} / 100$ calcium acetate so that the concentration of $\alpha$-amylase became $1 \%$ $\left(E_{280}^{1 \%}=25.3\right)$.

The thiolation was carried out by the method of Benesch and Benesch.8) To $150 \mathrm{ml}$ of the $\alpha$-amylase solution $(100)$ was added $435 \mathrm{mg}$ of AHTL by mechanical stirring and then $\mathrm{N} / 20$ silver nitrate equivalent to AHTL $(51.6 \mathrm{ml})$ was added dropwise while adjusting the $\mathrm{pH}$ at 7.5 with $\mathrm{N} / 20$ sodium hydroxide. The reaction mixture was allowed to react for $60 \mathrm{~min}$ at $25^{\circ} \mathrm{C}, \mathrm{pH} 7.5$, and then $18 \mathrm{ml}$ of cyanide buffer $\mathrm{pH} 7.4$, which was prepared by mixing $324 \mathrm{mg}$ of potassium cyanide, $5 \mathrm{ml}$ of $1.0 \mathrm{~N}$ tris (hydroxymethyl) aminomethane and $4.4 \mathrm{ml}$ of $2.1 \mathrm{~N}$ sulfuric acid was slowly added in the same way as above described. The yellowish clear solution was passed through the column containing Amberlite CG-400 Cl form; 20 mm-diameter and $260 \mathrm{~mm}$-long, buffered with $\mathrm{M} / 100$ calcium acetate. The eluate was dialysed against 15 liters of $\mathrm{m} / 100$ calcium acetate. The enzyme solution was stored at $-20^{\circ} \mathrm{C}$ until used.

Thiolation of PVA. SH-PVA was prepared by esterification of PVA with thioglycolic acid in the presence of hydrochloric acid.91 PVA (48 g) was dissolved in $192 \mathrm{ml}$ of water at $80^{\circ} \mathrm{C}$ and was added with $60 \mathrm{~g}$ of $80 \%$ thioglycolic acid and $10 \mathrm{ml}$ of $7 \mathrm{~N}$ hydrochloric acid. These were allowed to react for $120 \mathrm{~min}$ at $80^{\circ} \mathrm{C}$. The mixture was slowly poured into 1 liter of methanol in a Waring Blendor, and the white precipitate was collected on the Buchner funnel and the precipitate was washed repeatedly by using 6 liters of methanol. The product was preserved in methanol under nitrogen atmosphere at $5^{\circ} \mathrm{C}$ until used. 


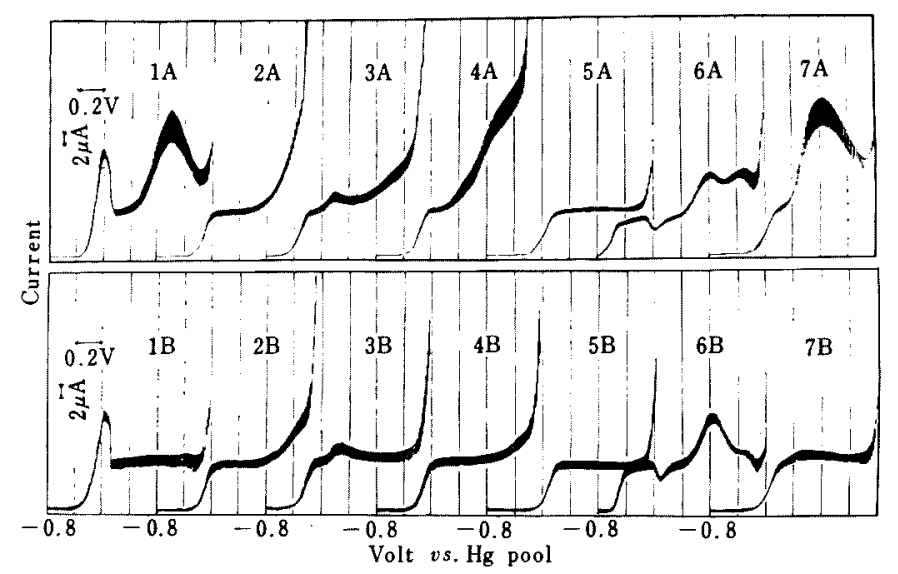

FIG. 1. Comparison of the Polarograms of Thiolated Polymers and Cysteine with or without the Original Polymers.

Supporting electrolyte: $\mathrm{NH}_{4} \mathrm{Cl} 0.1 \mathrm{M}, \mathrm{NH}_{4} \mathrm{OH} 0.1 \mathrm{M}$, cobalt salt $1 \mathrm{mM}$ (A: cobaltous chloride and B: hexamminecobaltic chloride). The final concentrations of samples: 1. CySH $5 \times 10^{-9} \mathrm{~mole} / \mathrm{ml} ; 2$. $\alpha$-amylase 0.25 $\mathrm{mg} / \mathrm{ml} ; 3$. SH-amylase $0.25 \mathrm{mg} / \mathrm{ml} ; 4 . \alpha$-amylase $0.25 \mathrm{mg} / \mathrm{ml}$ containing $5 \times 10^{-9}$ mole of CySH; 5. PVA $0.107 \mathrm{mg} / \mathrm{ml} ; 6$. SH-PVA $0.107 \mathrm{mg} / \mathrm{ml}$; 7. PVA $0.107 \mathrm{mg} / \mathrm{ml}$ containing $5 \times 10^{-9}$ mole of $\mathrm{CySH}$.

Chemical properties of thiolated derivatives. Thiol and disulfide contents ${ }^{10}$ of $\mathrm{SH}$-amylase were 2.2 moles and 3.8 moles per $100,000 \mathrm{~g}$, respectively. The result shows that 1 mole of $\alpha$-amylase was modified by 2.6 moles of N-acetylhomocysteine.

The thiolated enzyme was analyzed by disc electrophoresis. ${ }^{11}$ While the original $\alpha$-amylase was located as a single band, SH-amylase was separated to two main bands and three to four faint bands. The comparison of the results of the electrophoresis explained that one of the two main bands in the SHamylase gel corresponded to unreacted $\alpha$-amylase, another negative one was the enzyme whose amino groups were modified with $\mathrm{N}$-acetylhomocysteine and the others (the more positive faint components) were dimerization products of $\mathrm{SH}$-amylase or its degraded substances during thiolation.

Analysis of $\alpha$-amylase activity was done by SomogyiNelson method ${ }^{12}$ under the conditions of $\mathrm{pH} 5.9$ and $40^{\circ} \mathrm{C}$. Specific activities were found to be $7.4 \times 10^{2}$

10) R. E. Benesch, H. A. Lardy and R. Benesch, J. Biol. Chem., 216, 663 (1955).

11) B. J. Davis, Ann. New York Acad. Sci., 121, Art. 2, 404 (1964).

12) N. Nelson, J. Biol. Chem., 153, 375 (1944). and $5.8 \times 10^{2}$ units for the original and for the SH. amylase, respectively. Another experiment for the activity of each fraction separated by disc electrophoresis suggests that the decrease of activity of the apparent $\mathrm{SH}$-amylase which contains both unreacted and thiolated enzymes resulted mostly from instability of the unreacted enzyme.

SH-PVA was found to contain 1.3 mmoles of thiol per $g$ by argentmetric titration, 101 and 1.1 mmoles/g of sulfur by ashing procedure.131

\section{RESULTS AND DISCUSSION}

\section{Comparison of the polarograms of the thiolat-} ed polymers and cysteine

Thiolated derivatives of $\alpha$-amylase and PVA were analyzed by polarography. The results are shown in Fig. 1. SH-Amylase produced well-defined catalytic waves which have maximum peaks at -1.35 and -1.7 volt in cobaltous medium and at -1.35 volt in cobaltic

13) O. A. Krober and R. W. Howell, J. Agr. Food Chem., 6, 591 (1958). 
medium (Figs. 1-3A, 3B). Their peak potentials were similar to those of "protein waves."

The mixture of $\alpha$-amylase and cysteine represented catalytic waves only in the cobaltous electrolyte and it was inactive in the cobaltic medium (4A and $4 \mathrm{~B}$ in Fig. 1 ).

These observations support the suggestions that chemically incorporated thiol or disulfide groups are essential for generating "protein waves" in the range of the concentrations of sample and in the medium used in the present experiment.

The phenomenon in which the first wave appeared prominently at -1.35 volt and the second wave was almost undiscernible at -1.75 volt was very characteristic of $\mathrm{SH}$ amylase as compared with other ordinary "protein waves." Geometric position of thiol in the protein molecule must be a factor influencing the wave height and the shape of waves. Thiol groups exist far from the peptide main chain in the $\mathrm{SH}$-amylase molecule as compared with those of ordinary protein molecule. The distance of thiol and amino or other functional groups in the primary structure of proteins must affect the wave height and the shape of protein waves. It may be explained by the difficulty of its approach to the surface of electrode or the difficulty of its becoming complex with cobalt ions or some other mechanisms.

The other thiolated polymer, SH-PVA, also represented characteristic waves both in cobaltous and cobaltic solutions (Figs. 1-6A, $6 \mathrm{~B})$ whereas PVA mixed with cysteine was active only in divalent cobalt solution (Figs. 1-7A, 7B). Those results also support the necessity of chemical attachment of thiol groups to the polymer molecule for producing the waves similar to those of proteins with trivalent cobalt.

SH-PVA indicated a different behavior from "protein waves," that is, a round maximum peak appears at -1.0 volt, and simultaneously the cobalt wave shifted to more negative side and the "minimum effect,"," which returns to the level of the cobalt, was observed. SH-PVA is a linear compound consists of $-\mathrm{CH}_{2^{-}}$and $-\mathrm{CHOH}-$ which is partly esterified with thioglycolic acid. It contains no amino group but alcoholic hydroxyl group as a functional group. Hence, it may be possible that the latter group has some role on the catalytic reduction of hydrogen ions in the presence of thiol groups in a way different from that of protein.

It should be noted that the wave height per unit of thiol group in these two SHpolymers was smaller than in the case of ordinary protein. ${ }^{11}$ An amount $0.25 \mathrm{mg}$ of $\mathrm{SH}$ amylase used for analysis contained $1.45 \times 10^{-8}$ mole of thiol and $0.107 \mathrm{mg}$ of SH-PVA contained $1.39 \times 10^{-7}$ mole of thiol. The wave heights of SH-derivatives used are much smaller than that of cysteine $\left(5 \times 10^{-9}\right.$ mole) when the wave height per unit of thiol is considered as the criterion (Figs. 1-1A, 6A, $7 \mathrm{~A})$.

\section{Variation of polarograms with polymer con- centration}

The systems containing $0.1 \mathrm{M}$ ammonium chloride, $0.1 \mathrm{~m}$ ammonia, $1 \mathrm{mM}$ cobalt salt, and various amounts of SH-amylase or SH-PVA were analyzed by polarograph. The results were summarized in Fig. 2.

$\mathrm{SH}-$ Amylase represented a round maximum wave around -1.30 to -1.35 volt both in cobaltous and in cobaltic electrolytes (Fig. 2A), and the relation of wave height and $\mathrm{SH}$ amylase concentration was consistent with the Langmuir's adsorption isotherm; the concentration versus the wave height is monofunctional to the concentration. The second wave height at -1.65 volt in the trivalent cobalt solution also have the same relation to the concentration of SH-amylase. These fact can be seen from the results shown in Fig. 4-1A. The second wave in the cobaltous

14) M. Itoh, Ann. Rep. Prefect. Univ. Mie, Sect. 2, 3, 35 (1959). 

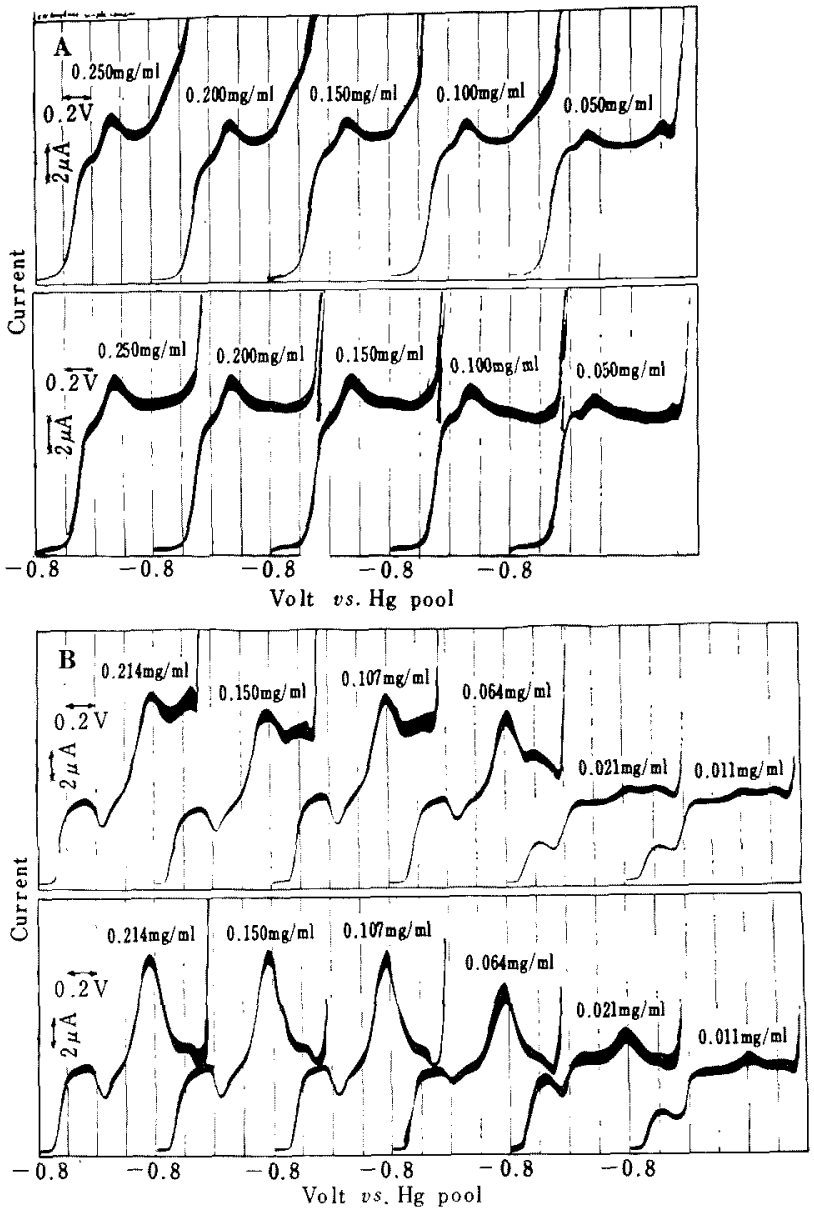

Frg. 2. Effect of the Concentrations of the Thiolated Derivatives.

Supporting electrolyte: $\mathrm{NH}_{4} \mathrm{Cl} 0.1 \mathrm{M}, \mathrm{NH}_{4} \mathrm{OH} 0.1 \mathrm{M}$, cobalt salt $\mathrm{I} \mathrm{mM}$ (the upper figures in $\mathrm{A}$ and $\mathrm{B}$ : cobaltous chloride, the lower figures: hexamminecobaltic chloride). A: concentrations of SH-amylase are $0.25,0.20,0.15,0.10$ and $0.05 \mathrm{mg} / \mathrm{ml}$ from left to right; $\mathrm{B}$ : concentrations of SH-PVA are $0.214,0.150,0.107,0.064,0.021$ and $0.011 \mathrm{mg} / \mathrm{ml}$ from left to right.

medium disappeared as it was overlapped by the wave which appeared at a higher voltage and which was non-specific to $\mathrm{SH}$-amylase (compare 2A with $3 \mathrm{~A}$ in Fig. 1).

The well-defined double waves also appeared with various concentrations of SH-PVA (Fig. 2-B). The first round wave at -1.6 volt and the second wave around -1.78 to -1.85 volt were found to be approximately identical to the adsorption isotherm under the range tested, when their values were plotted against the concentrations of samples (Fig. 4-1B).

These results seem to indicate that the double waves of thiolated derivatives are due to a 

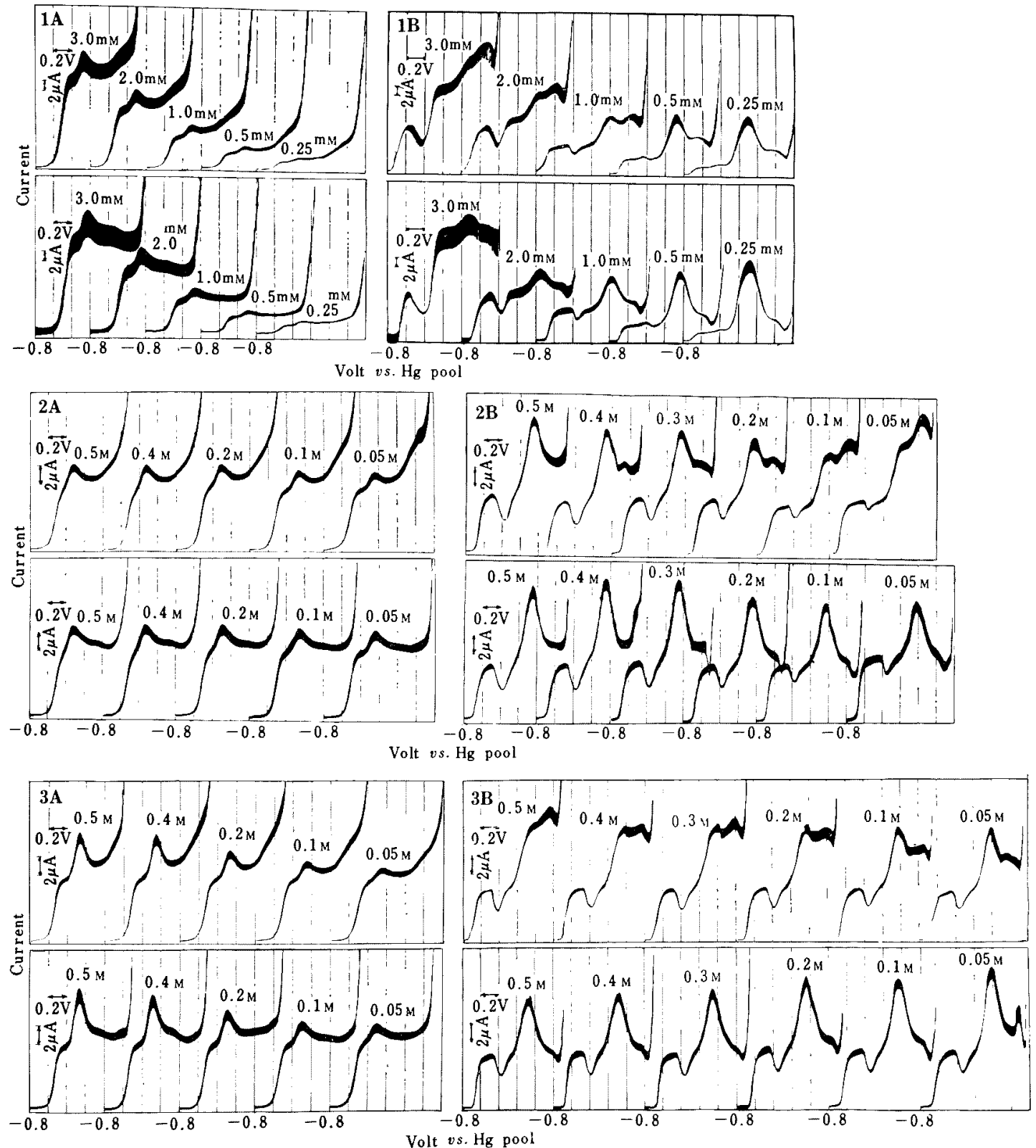

FIG. 3. Effect of the Concentrations of the Electrolyte Constituents on the Polarograms of SH-Polymers.

Standard electrolyte: $\mathrm{NH}_{4} \mathrm{Cl} 0.1 \mathrm{M}, \mathrm{NH}_{4} \mathrm{OH} 0.1 \mathrm{M}$, cobalt salt $1 \mathrm{~mm}$ (the upper figure of each combination: with cobaltous chloride, the lower figure: with hexamminecobaltic chloride). Sample concentrations: A. SH-amylase $0.25 \mathrm{mg} / \mathrm{ml} \mathrm{B}$. SH-PVA, $0.107 \mathrm{mg} / \mathrm{ml}$. Concentration of the electroIyte constituents changed; $1 \mathrm{~A}$ and $\mathrm{lB}: 3.0,2.0,1.0,0.5$ and $0.25 \mathrm{~mm}$ cobalt salt, $2 \mathrm{~A}$ and $2 \mathrm{~B}: 0.5$, $0.4,(0.3), 0.2,0.1$ and $0.05 \mathrm{M} \mathrm{NH}_{4} \mathrm{Cl}, 3 \mathrm{~A}$ and $3 \mathrm{~B}: 0.5,0.4,(0.3), 0.2,0.1,0.05 \mathrm{M} \mathrm{NH} \mathrm{OH}_{\text {from }}$ left to right. 
catalytic reaction of the derivatives adsorbed upon the surface of the electrode.

The maximum wave, preceeding to the cobalt wave in the polarograms of SH-PVA which may be named "precobalt wave," shifted to a more negative potential, and its wave height increased with the increasing concentration of SH-PVA. The latter increment ceased at the same level of the cobalt wave when the concentration of SH-PVA became $0.64 \mathrm{mg} / \mathrm{ml}$. It might be true that the co-existence of cobalt and thiol groups was necessary for producing "precobalt wave."

3. Effect of electrolyte constituents on the polarograms of the thiolated derivatives

Effect of the cobalt concentration. Concentration of cobalt salt was decreasingly changed from $3 \mathrm{~mm}$ to $0.25 \mathrm{~mm}$ as shown in Fig. 3-1A and 1B. A well-defined round maximum wave was observed throughout the concentrations tested. It moved to a more negative potential with the increasing concentration. The second wave was distinct at -1.7 volt for $\mathrm{SH}-a m y l a s e$ and around -1.5 to -1.6 volt for SH-PVA, but that of SH-amylase in cobaltous electrolyte was overlapped by the reduction wave of hydrogen ion.

The wave heights were plotted against the concentrations of electrolyte components (Fig. 4). The wave heights were thus shown to increase with the increasing cobalt concentration in the case of SH-amylase as has been observed in ordinary "protein waves."14 On the contrary, SH-PVA represented a particular feature - the wave heights decreased by the increasing concentration of cobalt salt. The similar effect has been observed in the case of thiolated casein. ${ }^{51}$

Sunahara et al. observed "minimum effect" on the polarography of oxytocin derivatives, and concluded that "minimum effect" became distinct with the decrease in free amino groups." At present, however, the role of amino group on "minimum effect" remains obscure because it was observed both in $\mathrm{SH}$ - amylase and SH-PVA.

"Precobalt wave" of SH-PVA appeared throughout the concentrations used and it shifted to more positive potential with increasing cobalt concentration. The wave heights increased with increasing cobalt concentration until $1 \mathrm{~mm}$ and became constant at the higher concentration. The behavior of "precobalt wave," which was shown above

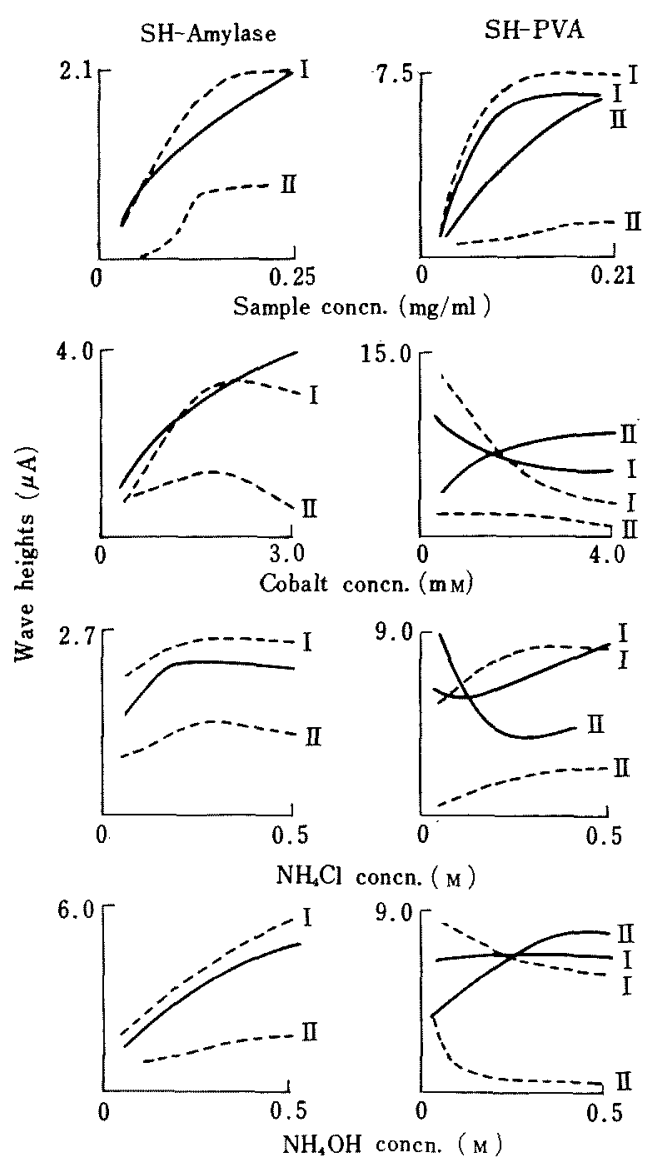

FIG. 4. Relationship between the Wave Heights and the Concentrations of Samples and Electrolyte.

Curves were drawn from the values measured in Fig. 2 and Fig. 3. I and II denote the first wave and the second wave, respectively. Solid line: cobaltous electrolyte, dashed line: cobaltic electrolyte. 
and in the last section, suggests that the ratio of the concentrations of cobalt and SH-PVA is a height-determining factor-its wave height increased with the increase of the ratio up to the same height as cobalt wave.

Effect of the concentration of either ammonium chloride or ammonia. Concentrations of ammonium chloride and ammonia were changed from 0.05 to $0.5 \mathrm{M}$, the concentrations of other component being kept constant. The polarograms are shown in Fig. 3.

$\mathrm{SH}$-Amylase showed a similar phenomenon to natural proteins, that is, the wave heights increased with the increasing concentration of ammonia or ammonium chloride.

The shape of the waves of SH-PVA was changed markedly by the change of buffer component especially in cobaltous electrolyte. The first wave was smaller than the second in the electrolyte containing either the lower concentration of ammonium chloride or the higher concentration of ammonia. The reverse relation between the first and the second waves was observed in the medium containing the higher concentration of ammonium chloride or the lower concentration of ammonia. It is summarized in Fig. 4-3B, 4B. From the figure the first wave seems less sensible to the relative concentration of ammonium chloride and ammonia whereas the second wave was prominently raised with increasing ratio of concentration of ammonia to ammonium chloride. With cobaltic salt, the second wave was more remarkable in the lower concentration of ammonia. These dependence of the catalytic waves of SH-PVA upon the concentration of ammonium buffer was different from that of ordinary "protein waves."

So-called "minimum effect" was found in the polarograms of SH-PVA in cobaltic medium under the higher concentrations of ammonia.

\section{GENERAL DISCUSSION}

In order to clarify the mechanism of the protein wave which is produced in the ammoniacal cobalt solution, two thiolated polymers of natural and synthetic substances were employed as model samples. The original materials were polarographically inactive as far as their catalytic effect was concerned. The incorporation of thiol groups to them caused appearance of a typical catalytic effect on the polarography in the ammoniacal buffer containing either trivalent or divalent cobalt salt. The results confirmed the hitherto-known hypothesis that the chemical attachment of thiol group to the polymer structure is essential for production of protein waves.

The SH-amylase used in this experiment was found to show the polarographic behavior similar to that of protein at the points shown below: 1) the wave height was increased with the increasing concentrations of electrolyte components, cobalt salt, ammonium chloride or ammonia, 2) its double waves suggested the two-steps catalytic effect of the enzyme on the reduction of hydrogen ion at the same potentials as in the case of ordinary proteins. However, the fact that its wave height per thiol was smaller than that of ordinary "protein waves," "14l could be explained from the molecular structure including the distance between thiol group and the peptide main chain in the primary structure.

Another model compound, PVA, consists of $\left(-\mathrm{CH}_{2} \mathrm{CHOH}-\right)_{n}$ and contains neither amino nor carboxyl group. However, its thiolated derivative showed a catalytic effect, and the cysteine mixed with the original polymer did not show any wave in cobaltic medium. It seems likely that the chemical incorporation of thiol group facilitates the formation of the complex between cobalt ion and thiol group and its approach to the electrode is primarily easier for high molecular thiol compounds than for simple compounds such as cysteine.

The present experiments may suggest that the specific protein wave may be brought about by the following two conditions,

(1) the specific tendency of the thiol group 
making complex with cobaltic and cobaltous ion in ammoniacal buffer, and

(2) the specific reaction which makes this complex approach to and separate from the electrode through catalytic process.
Acknowledgement. The authors wish to express their gratitude to Professor T. Hata, Kyoto University for his useful suggestions. 